\title{
Prevalence of the metabolic syndrome in patients with carotid disease according to NHLBI/AHA and IDF criteria: a cross-sectional study
}

\author{
Milos Z Maksimovic ${ }^{*}$, Hristina D Vlajinac ${ }^{2}$, Djordje J Radak ${ }^{3}$ Jelena M Marinkovic ${ }^{4}$ and Jagoda B Jorga ${ }^{1}$
}

\begin{abstract}
Background: Metabolic syndrome (MetS) has been related to type 2 diabetes and cardiovascular diseases. Different criteria for diagnosis of MetS have been recommended, but there is no agreement about which criteria are best to use. The aim of the present study was to investigate agreement between the National Heart, Lung, and Blood Institute, American Heart Association (NHLBI/AHA) and the International Diabetes Federation (IDF) definitions of MetS in patients with symptomatic carotid disease and to compare the frequency of cardiovascular risk factor in patients with MetS diagnosed by these two sets of criteria.

Methods: The study was a cross-sectional one involving 644 consecutive patients with verified carotid disease who referred to the Vascular Surgery Clinic Dedinje in Belgrade during the period April 2006 - November 2007.

Anthropometric parameters blood pressure, fasting plasma glucose and lipoproteins were measured using standard procedures.

Results: MetS was present in $67.9 \%$ of participants, according to IDF criteria, and in $64.9 \%$ of participants, according to the NHLBI/AHA criteria. A total of 119 patients were categorized differently by the two definitions. Out of all participants $10.7 \%$ had MetS by IDF criteria only and $7.8 \%$ of patients had MetS by NHLBI/AHA criteria only. The overall agreement of IDF and NHLBI/AHA criteria was 81.5\% (Kappa 0.59, $p<0.001$ ). In comparison with patients who met only IDF criteria, patients who met only NHLBI/AHA criteria had significantly more frequently cardiovascular risk factors with the exception of obesity which was significantly more frequent in patients with MetS diagnosed by IDF criteria.
\end{abstract}

Conclusion: The MetS prevalence in patients with symptomatic carotid disease was high regardless of criteria used for its diagnosis. Since some patients with known cardiovascular risk factors were lost by the use of IDF criteria it seems that NHLBI/AHA definition is more suitable for diagnosis of MetS. Large follow-up studies are needed to test prognostic value of these definitions.

Keywords: metabolic syndrome, carotid disease, risk factors

\section{Background}

During the last two decades metabolic syndrome (MetS) has become one of the major public-health challenges worldwide [1]. In 1988 Reaven was first to describe Syndrome $\mathrm{X}$, and defined it as a cluster of hypertension, glucose intolerance, elevated tryglycerides and low level of high density lipoprotein (HDL) cholesterol [2].

\footnotetext{
* Correspondence: milos.maksimovic@mfub.bg.ac.rs

'Institute of Hygiene and Medical Ecology, Faculty of Medicine, University of Belgrade, Serbia

Full list of author information is available at the end of the article
}

Ferrannini et al. suggested that this clustering was caused by insulin resistance and called it insulin resistance syndrome [3]. World Health Organization (WHO) defined the syndrome and changed its name to metabolic syndrome [4]. In 2001 the National Cholesterol Education Program - Adult treatment Panel III (NCEPATP III) proposed both diagnostic criteria for metabolic syndrome and cut-off points for its components (abdominal obesity, hypertension, increased level of triglycerides and fasting plasma glucose and low level of HDL- C) [5]. NCEP-ATP III criteria were revised in

\section{Ciomed Central}


2005 by the American Heart Association (AHA) and the National Heart, Lung, and Blood Institute (NHLBI) modified NCEP-ATP III criteria, called also NHLBIAHA criteria [6], and in 2006 International Diabetes Federation recommended a new definition of metabolic syndrome - IDF definition [7].

According to the literature data, the prevalence of MetS depends on the definition used [8-11]. The concordance between various definitions has most frequently been high $[9,10]$, although there are some subjects in whom MetS was diagnosed by one definition only and not by other(s). There is no agreement about which criteria for MetS diagnose are best to use.

The aim of the present study was to investigate agreement between the NHLBI/AHA and the IDF definitions of MetS in patients with symptomatic carotid disease and to compare the frequency of cardiovascular risk factor in patients with MetS diagnosed by these two sets of criteria.

\section{Methods}

The study used for the present investigation was crosssectional. It involved consecutive patients with verified carotid disease who referred to the Vascular Surgery Clinic Dedinje in Belgrade during the period April 2006 - November 2007. In the study were included 644 subjects who had symptoms of cerebral ischemia and carotid stenosis of $\geq 50 \%$, according to NASCET criteria [12]. Carotid atherosclerosis was estimated by high resolution B-mode ultrasonography.

Patients under eighteen years of age, with malignant disease, previous endarectomy or rheumatoid arthritis, were excluded.

For all participants anthropometric parameters and data on cardiovascular risk factors were collected.

Waist circumference was measured at the midway between lower rib and crista iliaca according to WHO recommendations [13].

Body weight was assessed by using a calibrated standard balance-beam, height was measured by a standard height bar, and Body Mass Index (BMI) was calculated as weight $(\mathrm{kg})$ divided by height $\left(\mathrm{m}^{2}\right)$ [13]. Percent of body fat was assessed according to the method proposed by Durnin and Womerslaj [14].

Blood pressure was measured using the method recommended by the Seventh Report of the Joint National Committee on Prevention, Detection, Evaluation, and Treatment of High Blood Pressure [15].

For estimation of metabolic parameters, fasting plasma glucose (FPG) and lipoproteins, blood samples were obtained after an overnight fast and avoidance of liquids. Levels of fasting plasma glucose (FPG), total cholesterol (TC), serum triglycerides (TG), high-density lipoprotein cholesterol (HDL-C), low-density lipoprotein cholesterol
(LDL-C) and serum uric acid level were estimated using commercial kits (Abbot, IL, USA) on an automated analyzer (AEROSETTM, Abbot, IL, USA). Levels of high sensitivity C-reactive protein (hsCRP) and fibrinogen were measured by using Immunoturbidimetric fixed time test (Olympus Diagnostics, O'Callaghan's Mills Co. Clare, Ireland).

According to NHLBI/AHA criteria [6] metabolic syndrome was diagnosed when three or more of the following risk factors were present: abdominal obesity (> 102 $\mathrm{cm}$ in men, and $>88 \mathrm{~cm}$ in women), hypertension $\geq$ $130 / \geq 85 \mathrm{mmHg}$ or specific medication, level of triglycerides $\geq 150 \mathrm{mg} / \mathrm{dl}(1.7 \mathrm{mmol} / \mathrm{L})$ or specific medication, low HDL cholesterol: in men $<40 \mathrm{mg} / \mathrm{dl}(1.03$ $\mathrm{mmol} / \mathrm{L})$, and in women $<50 \mathrm{mg} / \mathrm{dl}(1.29 \mathrm{mmol} / \mathrm{L})$ or specific medication, and fasting plasma glucose $\geq 100$ $\mathrm{mg} / \mathrm{dl}(5.6 \mathrm{mmol} / \mathrm{L})$ or history of diabetes mellitus or taking antidiabetic medications.

According to the IDF criteria MetS include abdominal obesity ( $>94 \mathrm{~cm}$ in men, and $>80 \mathrm{~cm}$ in women), plus any two of the same risk factors as in NHLBI/AHA criteria: hypertension $\geq 130 / \geq 85 \mathrm{mmHg}$ or antihypertensive therapy, level of triglycerides $\geq 150 \mathrm{mg} / \mathrm{dl}(1.7$ $\mathrm{mmol} / \mathrm{L}$ ) or specific medication, low HDL cholesterol: in men $<40 \mathrm{mg} / \mathrm{dl}(1.03 \mathrm{mmol} / \mathrm{L})$, and in women $<50$ $\mathrm{mg} / \mathrm{dl}(1.29 \mathrm{mmol} / \mathrm{L})$ or specific medication, and fasting plasma glucose $\geq 100 \mathrm{mg} / \mathrm{dl}(5.6 \mathrm{mmol} / \mathrm{L})$ or history of diabetes mellitus or taking antidiabetic medications.

\section{Statistical analysis}

Categorical variables were presented by counts and percentages. Continuous variables were described as means with 95\% confidence interval. Kappa statistics was used to measure agreement between the two criteria. ANOVA was applied for mutual comparisons of cardiovascular risk factors in subjects with MetS according to IDF, NHLBI/AHA and both criteria and subjects without MetS, as well as for comparison of cardiovascular risk factors among gender. Data were analyzed using SPSS package version 15 with significance level set to 0.05 .

The study was reviewed and given ethical approval by the Ethics Committee at the Faculty of Medicine in Belgrade. All patients gave written, informed consent.

\section{Results}

The study included 644 patients with symptomatic carotid disease, $402(62.4 \%)$ males and 242 (37.6\%) females (Table 1).

Of 644 patients, 437 (67.9\%) had metabolic syndrome according to IDF criteria and 418 (64.9\%) according to the NHLBI/AHA criteria. The prevalence of metabolic syndrome was $60.9 \%$ in males and $79.3 \%$ in females according to the IDF criteria, and $61.4 \%$ in males and 
Table 1 Frequency of metabolic syndrome by IDF and NHLBI/AHA criteria

\begin{tabular}{|c|c|c|c|c|c|}
\hline & $\begin{array}{l}\text { Without MetS } \\
\text { Number (\%) }\end{array}$ & $\begin{array}{l}\text { MetS by both criteria } \\
\text { Number (\%) }\end{array}$ & $\begin{array}{l}\text { MetS by IDF only } \\
\text { Number (\%) }\end{array}$ & $\begin{array}{l}\text { MetS by NHLBI/AHA only } \\
\text { Number (\%) }\end{array}$ & Chi square ( $p$ value) ${ }^{\text {a }}$ \\
\hline All participants $(n=644)$ & $157(24.4)$ & $368(57.1)$ & $69(10.7)$ & $50(7.8)$ & \\
\hline \multicolumn{6}{|l|}{ Gender: } \\
\hline Male $(n=402)$ & $113(28.1)$ & $203(50.5)$ & $42(10.4)$ & $44(10.9)$ & \\
\hline Female $(n=242)$ & $44(18.2)$ & $165(68.2)$ & $27(11.2)$ & $6(2.5)$ & $28.39(<0.001)$ \\
\hline \multicolumn{6}{|l|}{ Age group: } \\
\hline $35-54(n=78)$ & $20(25.6)$ & $34(43.6)$ & $13(16.7)$ & $11(14.1)$ & \\
\hline $55-64(n=199)$ & $42(21.1)$ & $123(61.8)$ & $23(11.6)$ & $11(5.5)$ & \\
\hline $65-69(n=144)$ & $34(23.6)$ & $93(64.6)$ & $11(7.6)$ & $6(4.2)$ & \\
\hline $70-74(n=142)$ & $32(22.5)$ & $82(57.7)$ & $12(8.5)$ & $16(11.3)$ & \\
\hline$\geq 75(n=81)$ & $29(35.8)$ & $36(44.4)$ & $10(12.3)$ & $6(7.4)$ & $27.29(0.007)$ \\
\hline
\end{tabular}

${ }^{a}$ Chi-square tests was performed to assess variations in the distribution of patients among the four metabolic syndrome categories by sex and age.

$70.7 \%$ in females according to the NHLBI/AHA criteria. A total of 119 patients were categorized differently by the two definitions. Out of all participants $69(10.7 \%)$ had MetS only by IDF criteria (42 males and 27 females), and 50 (7.8\%) patients had MetS only by NHLBI/AHA criteria.

The overall agreement of IDF and NHLBI/AHA criteria was $81.5 \%$ (Kappa 0.59, $p<0.001$ ). There were significant differences in agreement between the two metabolic syndrome definitions based on sex and age. In males agreement was 78.6\% (Kappa 0.55, $p<0.001$ ) and in females $86.4 \%$ (Kappa $0.64 p<0.001$ ). For age groups agreement ranged from 69.2\% (Kappa $=0.36, \mathrm{p}<0.001)$, for subjects $35-54$ years old, to $88.2 \%$ (Kappa $=0.72, \mathrm{p}$ $<0.001$ ), for subjects 65-69 years old."

Comparisons of cardiovascular risk factors in patients with metabolic syndrome diagnosed by IDF and NHLBI/ AHA criteria, and in patients without metabolic syndrome, are presented in Table 2 and Table 3.

According to data presented in Tables 2 and 3, the greatest differences in cardiovascular risk factors were found between patients with MetS diagnosed by both criteria and patients without MetS. Patients with MetS were significantly more obese (BMI, WC and \% of body fat) and had significantly higher mean values of sistolic and diastolic blood pressure, triglycerides, fasting blood glucose and serum uric acid and significantly lower mean value of HDL - C. In comparison with patients without MetS, patients in whom MetS was diagnosed only by IDF criteria had significantly higher mean values of BMI and \% of body fat and lower values of HDL-C. Comparing with patients without MetS, those in whom MetS was diagnosed only by NHLBI/AHA criteria had significantly higher mean values of systolic blood pressure, triglycerides and fasting plasma glucose, and lower values of HDL-C. Significant differences in cardiovascular risk factors were found between patients with MetS diagnosed by only one of the two criteria and patients with MetS diagnosed by both criteria. In comparison with patients in whom MetS was diagnosed by both criteria, patients who met only IDF criteria were significantly less obese (lower mean values of BMI, WC and \% body fat), had significantly lower mean levels of triglycerides, glucose and serum uric acid and higher mean level of HDL - C, while subjects who met only NHLBI/ AHA criteria were only significantly less obese (lower mean levels of BMI, WC and \% of body fat). In comparison with patients who met only NHLBI/AHA criteria, patients who met only criteria for IDF definition were significantly more obese (higher values of BMI, WC and $\%$ of body fat), but they had significantly lower mean level of glucose and higher mean level of HDL - C.

Patients who met only NHLBI/AHA criteria had significantly more frequently hypertension, elevated triglyceride and glucose level and a low HDL-C level in comparison with patients who met only IDF criteria (Table 4).

Analyses of drug treatment in patients (antihypertensive, hipolipidemic and for diabetes mellitus type 2) did not change differences in observed cardiovascular risk factors between compared groups (data not shown).

\section{Discussion}

In the present study metabolic syndrome prevalence in patients with symptomatic carotid disease was high regardless of criteria used for its diagnosis. According to IDF criteria MetS had $67.9 \%$ of patients, and according to the NHLBI/AHA criteria $64.9 \%$ of patients. The two definitions were concordant in $81.5 \%$ of patients (Kappa $0.59, p<0.001)$. In comparison with patients who met only IDF criteria, patients who met only NHLBI/AHA criteria had significantly more frequently cardiovascular risk factors with the exception of obesity which was significantly more frequent in patients with MetS diagnosed by IDF criteria. 
Table 2 Mean values of cardiovascular risk factors in patients with metabolic syndrome according to IDF and NHLBI/ AHA criteria and in patients without metabolic syndrome

\begin{tabular}{|c|c|c|c|c|}
\hline & $\begin{array}{l}\text { Without MetS } \\
(\mathrm{n}=157) \\
\text { Mean }(95 \% \mathrm{Cl})\end{array}$ & $\begin{array}{l}\text { MetS by both criteria } \\
(\mathrm{n}=368) \\
\text { Mean }(95 \% \mathrm{Cl})\end{array}$ & $\begin{array}{l}\text { MetS by IDF only } \\
(\mathrm{n}=69) \\
\text { Mean }(95 \% \mathrm{Cl})\end{array}$ & $\begin{array}{l}\text { MetS by NHLBI/AHA only } \\
(\mathrm{n}=50) \\
\text { Mean }(95 \% \mathrm{Cl})\end{array}$ \\
\hline Age (years) & $65.7(64.4,67.1)$ & $65.3(64.5,66.0)$ & $63.7(61.5,65.9)$ & $64.9(62.5,67.4)$ \\
\hline Body mass index $\left(\mathrm{kg} / \mathrm{m}^{2}\right)$ & $24.4(23.9,25.0)$ & $29.0(26.8,27.4)$ & $25.8(25.3,26.3)$ & $23.4(22.8,24.1)$ \\
\hline Waist circumference $(\mathrm{cm})$ & $89.9(88.2,91.7)$ & $102.6(101.7,103.6)$ & $92.0(90.3,93.6)$ & $87.2(85.6,88.9)$ \\
\hline$\%$ of body fat & $27.7(26.6,28.7)$ & $34.2(33.6,34.9)$ & $30.8(29.3,32.2)$ & $26.8(25.4,28.2)$ \\
\hline Systolic blood pressure $(\mathrm{mmHg})$ & $138.1(134.8,141.2)$ & $144.3(142.4,146.2)$ & $141.9(137.1,146.7)$ & $147.1(141.2,153.0)$ \\
\hline Diastolic blood pressure (mmHg) & $80.4(78.6,82.1)$ & $84.1(83.0,85.0)$ & $82.0(79.2,84.9)$ & $81.7(79.0,84.3)$ \\
\hline Triglycerides (mmol/L) & $1.3(1.2,1.3)$ & $2.2(2.1,2.3)$ & $1.5(1.4,1.6)$ & $1.9(1.7,2.1)$ \\
\hline Total cholesterol (mmol/L) & $5.2(5.0,5.4)$ & $5.3(5.2,5.4)$ & $5.1(4.8,5.3)$ & $5.3(4.9,5.6)$ \\
\hline $\mathrm{HDL}-\mathrm{C}(\mathrm{mmol} / \mathrm{L})$ & $1.2(1.1,1.3)$ & $1.0(1.0,1.0)$ & $1.1(1.0,1.6)$ & $0.9(0.9,1.0)$ \\
\hline $\mathrm{LDL}-\mathrm{C}(\mathrm{mmol} / \mathrm{L})$ & $3.5(3.3,3.6)$ & $3.4(3.3,3.5)$ & $3.2(3.0,3.5)$ & $3.4(3.1,3.8)$ \\
\hline Fasting plasma glucose (mmol/L) & $4.8(4.6,4.9)$ & $5.8(5.6,6.0)$ & $5.0(4.8,5.2)$ & $6.1(5.4,6.7)$ \\
\hline hsCRP (mg/L) & $4.7(3.5,5.9)$ & $4.0(3.4,4.6)$ & $3.9(2.6,5.3)$ & $2.6(1.7,3.6)$ \\
\hline Fibrinogen $(\mathrm{g} / \mathrm{L})$ & $3.4(3.3,3.6)$ & $3.4(3.3,3.5)$ & $3.4(3.1,3.7)$ & $3.2(2.9,3.5)$ \\
\hline Serum uric acid $(\mu \mathrm{mol} / \mathrm{L})$ & $315.2(302.8,327.6)$ & $356.3(346.6,366.1)$ & $325.0(307.1,342.9)$ & $326.9(302.0,351.9)$ \\
\hline
\end{tabular}

HDL - C: High density lipoprotein cholesterol; LDL - C: Low density lipoprotein cholesterol; hsCRP: high sensitivity C reactive protein.

The high prevalence of MetS in this study could be expected since it is known that the MetS prevalence is high in population with verified atherosclerotic disease. For example, according to Gorter et al. study [16], the prevalence of MetS in various types of atherosclerotic disease was in range from $41 \%$ in patients with coronary heart disease, up to $58 \%$ in patients with peripheral arterial disease.

The high agreement of two definitions is also not surprising taking into account the fact that these definitions had the same five components and that four of these components are defined identically. IDF and NHLBI/ AHA, vary in two important aspects. First, in the IDF criteria cut-off values for waist circumfernece are lower than in modified NCEP criteria (NHLBI/AHA), and the second and crucial, abdominal obesity is required as a prerequisite for diagnosis of MetS.

Similar results were found in other studies. The majority of these studies were performed in the samples of total populations and only few of them in patients with clinical atherosclerotic disease. In Li et al. study [10] the prevalence of MetS by NHLBI/AHA definition

Table 3 Significant ${ }^{a}$ differences in cardiovascular risk factors in subjects with metabolic syndrome according to IDF, NHLBI/AHA criteria, and patients without metabolic syndrome

\begin{tabular}{|c|c|c|c|c|c|c|}
\hline \multirow[t]{3}{*}{ Variable } & & & $\begin{array}{l}\text { Metabolic syndrome } \\
\text { according to: }\end{array}$ & \multirow[b]{2}{*}{$\begin{array}{l}\text { IDF criteria only } \\
\text { compared to: }\end{array}$} & & \multirow[b]{2}{*}{$\begin{array}{l}\text { NHLBI/AHA criteria } \\
\text { only compared to: }\end{array}$} \\
\hline & $\begin{array}{l}\text { Both criteria } \\
\text { compared to: }\end{array}$ & & & & & \\
\hline & Without MetS & $\begin{array}{l}\text { MetS by } \\
\text { IDF only }\end{array}$ & $\begin{array}{c}\text { MetS by NHLBI/AHA } \\
\text { only }\end{array}$ & $\begin{array}{l}\text { Without } \\
\text { MetS }\end{array}$ & $\begin{array}{c}\text { MetS by } \\
\text { NHLBI/AHA } \\
\text { only }\end{array}$ & $\begin{array}{l}\text { Without } \\
\text { MetS }\end{array}$ \\
\hline Body mass index $\left(\mathrm{kg} / \mathrm{m}^{2}\right)$ & $<0.001$ & $<0.001$ & $<0.001$ & 0.043 & 0.001 & - \\
\hline Waist circumference $(\mathrm{cm})$ & $<0.001$ & $<0.001$ & $<0.001$ & - & 0.034 & - \\
\hline$\%$ of body fat & $<0.001$ & $<0.001$ & $<0.001$ & 0.003 & 0.004 & - \\
\hline $\begin{array}{l}\text { Systolic blood pressure } \\
(\mathrm{mmHg})\end{array}$ & 0.006 & - & - & - & - & 0.003 \\
\hline $\begin{array}{l}\text { Diastolic blood pressure } \\
(\mathrm{mmHg})\end{array}$ & 0.001 & - & - & - & - & - \\
\hline Triglycerides (mmol/L) & $<0.001$ & $<0.001$ & - & - & - & 0.001 \\
\hline $\mathrm{HDL}-\mathrm{C}(\mathrm{mmol} / \mathrm{L})$ & $<0.001$ & 0.037 & - & 0.029 & 0.015 & $<0.001$ \\
\hline $\begin{array}{l}\text { Fasting plasma glucose } \\
(\mathrm{mmol} / \mathrm{L})\end{array}$ & $<0.001$ & 0.001 & - & - & 0.002 & $<0.001$ \\
\hline Serum uric acid ( $\mu \mathrm{mol} / \mathrm{L})$ & $<0.001$ & 0.045 & - & - & - & - \\
\hline
\end{tabular}

\footnotetext{
${ }^{a} p$ value according to ANOVA; HDL - C: High density lipoprotein cholesterol
} 
Table 4 Frequency of metabolic syndrome components in patients with metabolic syndrome according to IDF and NHLBI/AHA criteria

\begin{tabular}{|c|c|c|c|c|c|}
\hline \multirow[t]{3}{*}{ Metabolic syndrome component } & Without MetS & MetS by both criteria & MetS by IDF only & $\begin{array}{l}\text { MetS by NHLBI/ } \\
\text { AHA only }\end{array}$ & $p$ value $^{a}$ \\
\hline & $(n=157)$ & $(n=368)$ & $(n=69)$ & $(n=50)$ & \\
\hline & Number (\%) & $\begin{array}{l}\text { Number } \\
(\%)\end{array}$ & Number (\%) & $\begin{array}{l}\text { Number } \\
(\%)\end{array}$ & \\
\hline \multicolumn{6}{|l|}{ Waist circumference ${ }^{\mathrm{b}}$ : } \\
\hline IDF & $62(39.5)$ & $368(100.0)$ & $69(100.0)$ & $0(0.0)$ & \\
\hline NHLBI/AHA & $35(22.3)$ & $297(80.7)$ & $0(0.0)$ & $0(0.0)$ & \\
\hline Triglycerides $^{c}$ & $10(6.4)$ & $248(67.4)$ & $17(24.6)$ & $30(60.0)$ & $<0.001$ \\
\hline Fasting plasma glucose ${ }^{d}$ & $19(12.1)$ & $209(56.8)$ & $9(13.0)$ & $35(70.0)$ & $<0.001$ \\
\hline Hypertension ${ }^{e}$ & $110(70.1)$ & $351(95.4)$ & $60(86.9)$ & $49(98.0)$ & 0.032 \\
\hline $\mathrm{HDL}-\mathrm{C}^{f}$ & $60(38.2)$ & $320(49.7)$ & $52(75.4)$ & $49(98.0)$ & 0.001 \\
\hline \multicolumn{6}{|c|}{$\begin{array}{l}\text { For comparison between IDF criteria only and NHLBI/AHA criteria only; } p \text { values were not calculated for waist circumference because of the basic differences } \\
\text { between the two metabolic syndrome definitions. }\end{array}$} \\
\hline \multicolumn{6}{|c|}{ b $>94 \mathrm{~cm}$ in men and $>80 \mathrm{~cm}$ in women, by IDF criteria; $>102 \mathrm{~cm}$ in men and > $88 \mathrm{~cm}$ in women, by NHLBI/AHA criteria. } \\
\hline \multicolumn{6}{|l|}{${ }^{c} \geq 1.7 \mathrm{mmol} / \mathrm{L}$ or specific medication } \\
\hline \multicolumn{6}{|c|}{${ }^{\mathrm{d}} \geq 5.6 \mathrm{mmol} / \mathrm{L}$ or history of diabetes mellitus or taking antidiabetic medication. } \\
\hline \multicolumn{6}{|c|}{ e Systolic blood pressure $\geq 130 \mathrm{mmHg}$ or diastolic blood pressure $\geq 85 \mathrm{mmHg}$ or antihypertensive therapy. } \\
\hline \multicolumn{6}{|c|}{${ }^{\mathrm{f}}$ High density lipoprotein cholesterol $<1.03 \mathrm{mmol} / \mathrm{L}$ in $\mathrm{men}$, and $<1.29 \mathrm{mmol} / \mathrm{L}$ in women or specific medication. } \\
\hline
\end{tabular}

was $8.3 \%$ and by IDF definition $7.8 \%$. The agreement was $94.4 \%$ in men and $97.0 \%$ in women. According to Athryos et al. [9] cross-sectional analysis of representative sample of Greek adults, the prevalence of MetS was $22.6 \%$ by NHLBI/AHA and $18.3 \%$ by IDF criteria. In a cross-sectional study among Malays in Kuala Lumpur, the MetS was diagnosed in $41.4 \%$ and $38.2 \%$ participants using the NHLBI/AHA and the IDF criteria respectively [11]. The use of the IDF MetS definition in the population of the United States [17], led to a higher prevalence estimate of the MetS than the use of NHLBI/AHA definition, although the two definitions similarly classified $\sim 93 \%$ of the participants as having or not having the MetS. Out of four MetS definition (WHO, EGIR, NHLBI/AHA and IDF), applied in a population-based cross- sectional study in four population of the AsiaPacific region [18], the highest prevalence of MetS was obtained with the IDF definition. Hildrum et al. [8] found that the prevalence of IDF-defined MetS was $29.6 \%$, compared to $25.9 \%$ when using the NHLBI/AHA criteria. In a case-control study in which the association of first-ever acute ischemic non-embolic stroke with the MetS was investigated, the prevalence of MetS in the patients group was $57.1 \%$ by NHLBI/AHA and $69.9 \%$ by IDF criteria and $18.1 \%$ and $30.7 \%$ in the control group respectively. Among women with coronary artery disease, the prevalence of MetS was $70 \%$ and $74 \%$ by NHLBI/AHA and IDF criteria [19]. In all these studies differences in the prevalence of the MetS by two definitions were present, but they were not significant and not in the same direction. Yet, in some smaller or greater number of subjects, the MetS was diagnosed by only one of the two definitions.
What seems to be more important than the percentage of MetS diagnosed by one or the other definition, is which one of the two definitions better identifies subjects at high risk of cardiovascular diseases. According to Athryos et al. study [9], cardiovascular disease (CVD) prevalence was increased in the presence of MetS irrespective of the definition used, but this increase was more pronounced when NHLBI/AHA criteria were applied in comparison with IDF definition. NHLBI/AHA criteria were also better, in comparison with IDF criteria, in identifying the metabolically abnormal, but non-obese, groups known to be predisposed to type 2 diabetes and cardiovascular diseases [20]. Li et al. [10] found that in the patients with hypertension, the IDF defined MetS was more strongly associated with coronary heart disease than NHLBI/AHA defined MetS, but it was weakly or not associated with stroke. Milionis et al. [21] reported that the implementation of the IDF MetS definition, although substantially increased the number of elderly subjects labeled as having MetS, did not contribute to the identification of those at high risk of stroke. Comparing prognostic utility of the two definitions of MetS in postmenopausal women with angiographic coronary heart disease, Brown et al. [19] stated that their analysis suggested that both MetS definitions successfully identified a subset of women at high risk for future cardiovascular events. However, the number of patients differentially classified by the two definitions was small and there were few cardiovascular events overall, so that they were unable to draw firm conclusions about differences in the clinical characteristics or risk for cardiovascular clinical outcomes between these two definitions. 
In the present study we did not follow up the participants so we cannot be sure about prognostic value of any of the two definitions. However, cardiovascular risk factors were more frequently present or were more adverse in patients with MetS who met only NHLBI/ AHA criteria than in those who met only IDF criteria. Patients who met only NHLBI/AHA criteria differ less from patients whose MetS was diagnosed by both definitions than patients who met only IDF criteria. Since some patients with known cardiovascular risk factors were lost by the use of IDF definition it seems that NHLBI/AHA definition is more suitable for diagnosis of MetS. Similar to our findings, in the cross-sectional study in Malay cohort, Moy and Bulgiba [11] found that blood pressure, glucose, total cholesterol and triglycerides were more adverse in participants diagnosed by NHLBI/AHA criteria than in the IDF group. They concluded that their results suggested that central obesity should not be the prerequisite for the development of increased cardiometabolic risks and that for diagnosis of MetS was better to use NHLBI/AHA than IDF criteria, at least in their own population.

The main limitation of this study is its cross-sectional design. Prospective studies are needed to find out which of the two definitions, IDF or NHLBI/AHA, better determines adverse events associated with the MetS.

\section{Conclusion}

The MetS prevalence in patients with symptomatic carotid disease was high regardless of criteria used for its diagnosis. The two definitions were concordant in 81.5\% of patients, but since some patients with known cardiovascular risk factors were lost by the use of IDF definition, it seems that NHLBI/AHA definition is more suitable for diagnosis of MetS. Large follow-up studies are needed to test prognostic value of these definitions.

\section{Acknowledgements \\ Acknowledgment: This work was supported by Ministry of Science and Ecology, Serbia, through contract no. III41002 (2011-2014).}

\section{Author details}

${ }^{1}$ Institute of Hygiene and Medical Ecology, Faculty of Medicine, University of Belgrade, Serbia. ${ }^{2}$ Institute of Epidemiology, Faculty of Medicine, University of Belgrade, Serbia. ${ }^{3}$ Department of Vascular Surgery, Dedinje Cardiovascular Institute, Faculty of Medicine, Belgrade, Serbia. ${ }^{4}$ Institute of Medical Statistics and Informatics, Faculty of Medicine, Belgrade, Serbia.

\section{Authors' contributions}

MM and HV participated in the design of the study and in analysis and interpretation of data, and drafted the manuscript. DR and JJ participated in the design of the study. JM performed statistical analysis and participated in interpretation of data and drafting of the manuscript. All authors read and approved the final manuscript.

\section{Competing interests}

The authors declare that they have no competing interests.
Received: 2 September 2011 Accepted: 31 January 2012

Published: 31 January 2012

\section{References}

1. Eckel RH, Grundy SM, Zimmet PZ: The metabolic syndrome. Lancet 2005 , 365:1415-1428.

2. Reaven GM: Banting lecture 1988: role of insulin resistance in human disease. Diabetes 1988, 37:1595-1607.

3. Ferrannini E, Haffner SM, Mitchell BD, Stern MP: Hyperinsulinemia: the key feature of a cardiovascular and metabolic syndrome. Diabetologia 1991, 34:416-422.

4. WHO-International Society of Hypertension guidelines for the management of hypertension. J Hypertens 1999, 17:151-183.

5. Third report of the National Cholesterol Education Program (NECP) expert panel on detection, evaluation, and treatment of high blood cholesterol in adults (Adult Treatment panel III). Final report. Circulation 2002, 106:3143-3421.

6. Grundy SM, Cleeman JI, Daniels SR, Donato KA, Eckel RH, Franklin BA, Gordon DJ, Krauss RM, Savage PJ, Smith SC Jr, Spertus JA, Costa F: Diagnosis and management of the metabolic syndrome. An American Heart Association/National Heart, Lung, and Blood Institute Scientific Statement. Circulation 2005, 112:2735-2752.

7. Alberti KGMM, Zimmet PZ, Shaw JE, IDF Epidemiology Task Force Consensus Group: The metabolic syndrome: a new world-wide definition from the International Diabetes Federation consensus. Lancet 2005, 366:1059-1062

8. Hildrum B, Mykletun A, Hole T, Midthjell K, Dahl AA: Age-specific prevalence of the metabolic syndrome defined by the International Diabetes Federation and the National Cholesterol Education Program: the Norwegian HUNT 2 study. BMC Public Health 2007, 7:220.

9. Athyros VG, Ganotakis ES, Bathianaki M, Monedas I, Goudevenos IA, Papageorgiou AA: Awareness, treatment and control of the metabolic syndrome and its components: A Multicentre Greek Study. Hellenic J Cardiol 2005, 46:380-386.

10. Li WJ, Xue H, Sun $K$, Song XD, Wang YB, Zhen YS, Han YF, Hui RT: Cardiovascular risk and prevalence of metabolic syndrome by differing criteria. Chin Med J (Engl) 2008, 121:1532-1536.

11. Moy FM, Bulgiba A: The modified NCEP ATP III criteria maybe better than the IDF criteria in diagnosing Metabolic Syndrome among Malays in Kuala Lumpur. BMC Public Health 2010, 10:678.

12. Barnett HJM, Taylor DW, Eliasziw M, Fox AJ, Ferguson GG, Haynes RB, Rankin RN, Clagett GP, Hachinski VC, Sackett DL, Thorpe KE, Meldrum HE, Spence JD: Benefit of Carotid Endarectomy in Patients with Symptomatic Moderate or severe Stenosis. N Engl J Med 1998, 339:1415-1425.

13. World Health Organization.Obesity: Preventing and Managing the Global Epidemic. Geneva: WHO 1998.

14. Durnin JVGA, Womersley J: Body Fat assessed from Total Body Density and its Estimation from Skin fold Thickness; Measurements on 481 men and Women Aged from 16 to 72 Years. Br J Nutr 1974, 32:77-97.

15. Chobanian AV, Bakris GL, Black HR, Cushman WC, Green LA, Izzo JL Jr, Jones DW, Materson BJ, Oparil S, Wright JT Jr, Roccella EJ, Joint National Committee on Prevention, Detection, Evaluation, and Treatment of High Blood Pressure, National Heart and Blood Institute; National High Blood Pressure Education Program Coordinating Committee: Seventh Report of the Joint National Committee on Prevention, Detection, Evaluation, and Treatment of High Blood Pressure. Hypertension 2003, 42:1206-1252.

16. Gorter PM, Olijhoek JK, van der Graaf Y, Algra A, Rabelink TJ, Visseren FL, SMART Study Group: Prevalence of the metabolic syndrome in patients with coronary heart disease, cerebrovascular disease, peripheral arterial disease or abdominal aortic aneurysm. Atherosclerosis 2004, 173:363-369.

17. Ford ES: Prevalence of the metabolic syndrome defined by the International Diabetes Federation among adults in the U.S. Diabetes Care 2005, 28:2745-2749.

18. Lee C, Huxley R, Woodward M, Zimmet P, Shaw J, Cho N, Kim H, Viali S, Tominaga M, Vistisen D, Borch-Johnsen K, Colagiuri S: Comparisons of metabolic syndrome definitions in four populations of the Asia-Pacific region. Metab Syndr Relat Disord 2008, 6:37-46

19. Brown TM, Vaidya D, Rogers WJ, Waters DD, Howard BV, Tardif JC, Bittner V: Does Prevalence of the Metabolic Syndrome in Women with Coronary Artery Disease Differ by the ATP III and IDF Criteria? Journal of Women's Health 2008, 17:841-847. 
20. Yoon YS, Lee ES, Park C, Lee S, Oh SW: The new definition of metabolic syndrome by the international diabetes federation is less likely to identify metabolically abnormal but non-obese individuals than the definition by the revised national cholesterol education program: the Korea NHANES study. Int J Obes (Lond) 2007, 31:528-534

21. Milionis HJ, Kostapanos MS, Liberopoulos EN, Goudevenos J, Athyros VG, Mikhailidis DP, Elisaf MS: Different definitions of the metabolic syndrome and risk of first-ever acute ischaemic non-embolic stroke in elderly subjects. Int I Clin Pract 2007, 61:545-551.

\section{Pre-publication history}

The pre-publication history for this paper can be accessed here: http://www.biomedcentral.com/1471-2261/12/2/prepub

doi:10.1186/1471-2261-12-2

Cite this article as: Maksimovic et al:: Prevalence of the metabolic syndrome in patients with carotid disease according to NHLBI/AHA and IDF criteria: a cross-sectional study. BMC Cardiovascular Disorders 2012 12:2.

\section{Submit your next manuscript to BioMed Central} and take full advantage of:

- Convenient online submission

- Thorough peer review

- No space constraints or color figure charges

- Immediate publication on acceptance

- Inclusion in PubMed, CAS, Scopus and Google Scholar

- Research which is freely available for redistribution

Submit your manuscript at www.biomedcentral.com/submit 